\title{
XV CONGRESSO INTERNACIONAL DE ARQUEOLOGIA CLÁSSICA - UNIVERSIDADE DE AMSTERDÃ
}

O Congresso Internacional de Arqueologia Clássica, realizado entre 12 e 17 de julho de 1998 em Amsterdã, Holanda, foi organizado pelo Departamento de Arqueologia Mediterrânica e pelo Museu Allard Pierson (Universidade de Amsterdã) em nome da Associação Internacional de Arqueologia Clássica (AIAC). O tema do Congresso Classical Archaeology towards the third millenium, Reflections and perspectives, nas palavras de Herman Brijder, seu presidente, visou propiciar "o debate de questões fundamentais tais como: para onde caminha a Arqueologia clássica; quão 'clássica' ainda hoje ela é; quão fortes ainda são as suas relações com a Altertumswissenschaft. Assim a intenção do Congresso foi a de buscar avaliar antigos e novos métodos de investigação analisar o desenvolvimento havido durante o século XX e propor perspectivas para as novas gerações de estudantes e especialistas". (Caderno de Programa, p.5).

É importante observar que neste evento estiveram representados inúmeros grupos de pesquisa europeus e norte-americanos, destacando-se a presença de arqueólogos italianos que demonstraram intensa e muitas vezes inovadora atividade de pesquisa. Alemães e holandeses representam o segundo contingente mais numeroso sendo que estes últimos destacam-se com importantes projetos arqueológicos interdisciplinares e de longa duração, integrando universidades e instituições de pesquisa como é o caso do trabalho apresentado no poster de P. Attema e outros, Regional Pathways to complexity: Landscape and Settlement Dynamics in Early Italy. Este projeto é desenvolvido pelas $\mathrm{Ne}$ therland Organization for Advanced Research, o Groningen Archaeological Institute da Universidade de Groningen e o Archaeolgical Department da Universidade Livre de Amsterdã.

Os trabalhos do Congresso desenvolveram-se durante cinco dias com a apresentação de seis conferências, duzentas e três comunicações e trinta e quatro posters.

As sessões, 12 por dia, foram organizadas tematicamente, dando conta de assuntos fundamentais tanto para a pesquisa, quanto para a divulgação de resultados junto a um público mais amplo. Assim, as comunicações foram agrupadas de sorte a se articularem em eixos temáticos básicos: 1. Arqueologia de Campo, 2. Arqueometria, Restauro e Conservação e Arqueologia de Museus, 3. Arquitetura e Urbanismo, 4. Artefatos, 5. Questões sociais, econômicas e políticas, 6. Cultos, religião e Arqueologia funerária e 7. Iconografia e Iconologia.

Em nossa avaliação geral do Congresso, algumas tendências podem ser apontadas como norteadoras de pressupostos inovadores que vêm sendo incorporados pelos especialistas em Arqueologia Clássica em seus trabalhos.

Assim, ainda que do ponto de vista temático boa parte dos trabalhos tragam títulos tradicionais como por exemplo Comparative Study of Votive Practice at Paestum, Italy de Rebecca Miller Ammerman (Hamilton), observa-se que, na maioria, o tratamento dado aos estudos específicos não pode ser definido como "tradicional", ao contrário, constata-se sempre uma preocupação em ajustar os estudos empíricos às conceituações dos estudos arqueológicos atuais. Tal é o que ocorre na comunicação citada, em que a autora critica o estudo isolado de um santuário e propõe a investigação centrada no complexo de santuários de uma pólis, buscando analisar a prática cultual com um contexto amplificado. Unidades arqueológicas tradicionais como séries artefatuais, construções específicas, sítios individualizados, foram, na maioria das vezes, abordados sob novas óticas visando sempre a contextualização em quadros histórico-culturais mais abrangentes. Da mesma forma, materiais arqueológicos e informações arqueológicas obtidas, às vezes, até no século passado, foram apresentados em comunicações que demonstram uma rearticulação dos dados dentro de preocupações mais atuais ou através de métodos científicos mais recentes. Neste sentido, como exemplo, podemos citar a inserção dos sítios arqueológicos em estudos de caráter regional e a combinação de metodologias de disciplinas diversas como uma tendência recorrente em muitas comunicações. Tal é o caso da apresentação de P. Attema (Groningen) From the Early Latin to the Roman Colonial Landscape. Perspectives from the Pontine Region Field Survey, onde se propõe uma integração de métodos Survey, environmental research and 
pottery studies com o intuito de estudar as mudanças na organização dos assentamentos e do uso da terra em um longo período que vai da Idade do Bronze à época romana. No caso da comunicação de J.F.W. Koens e R.J. Jansen (Amsterdã) Computed Tomography and Ancient Ceramics: a new approach são apresentados os resultados obtidos pela aplicação desta nova técnica no aprofundamento do conhecimento a respeito das tecnologias cerâmicas.

Destacam-se igualmente temáticas completamente novas, buscando a inserção da Arqueologia no debate atual que cerca as Ciências que lidam com o passado do Homem. Assim várias comunicações e algumas das conferências de abertura ou de encerramento giraram em torno da questão da instrumentalização e do "consumo" do passado com finalidades modernas. Nessa linha de abordagem podemos citar a conferência de Manolis Korres The modern cult of ancient objects and monuments ou a de Ian Morris The Social and Economic Archaeology of Greece ou ainda a de Stephen L. Dyson Thomas Jefferson, Robber Barons and Multiculturalism: American Classical Archaeology from the city on the Hill to the new Millenium.

Posicionamentos polêmicos sobre temas antigos também foram apresentados suscitando debates produtivos e instigantes como aqueles apresentados nas comunicações de John H. Oakley Through a glass darkly I: misconceptions about the study of Greek vase painting e de Olga Palagia Through a glass darkly II: misconceptions about the study of Greek sculpture ou ainda as de W. van de Put CVA: Corpus or Corpse? e de Alexandra Coucouzeli (Cambridge) Architecture, Power, and Ideology in Dark Age Greece: A new interpretation of the Lefkandi toumba building.

A Seção de Posters, valorizou sobretudo a apresentação visual de resultados de pesquisas realizadas através de recursos técnicos e metodologias inovadoras como programas informatizados de manipulação de dados arqueológicos ou de divulgação de pesquisas. Podemos mencionar por exemplo, a comunicação de J.K. Papadopoulos
(Los Angeles) Virtual reality and Classical Archaeology: the Forum of Trajan revisited, ou a de C. Corsi e outros (Roma) Ricerche topografiche in Sicilia: Integrazione tra Metodi tradizionali e dati iperspettrali da piattaforma aerea, ou ainda a de P. Friedemann (Golion) La Souris, nouvelle outil de l'archéologie?.

A participação brasileira neste evento, ficou por conta do poster Classical Archaeology in Brazil: Developments and Perspectives onde procuramos enfatizar a criação, a partir da década de 1970 , de um núcleo de ensino e de pesquisa em torno da coleção de arqueologia clássica do Museu de Arqueologia e Etnologia da USP. O interesse que esta comunicação gerou nos congressistas foi de duas naturezas. Em primeiro lugar, para muitos era pouco conhecido o fato de existir uma coleção de Arqueologia Clássica no Brasil. Em segundo lugar, gerou interesse o fato de que esta coleção tenha vindo ao Brasil através de um intercâmbio científico. Com efeito, durante o Congresso foi levantado o sempre atual debate sobre a questão da aquisição de "antiguidades" por Museus e instituições científicas.

O que se pode observar como tendência em crescente aceitação entre os especialistas, é o apoio ao intercâmbio de artefatos, favorecendo a que países que dispõem de imensas coleções com objetos idênticos, na maioria das vezes empoeirando-se em reservas técnicas, possam livremente disponibilizálos a outros países, pelo mundo a fora, propiciando não só a multiplicação da pesquisa em Arqueologia clássica como possibilitando a um público mais amplo o acesso à Antigüidade. Neste sentido, o nosso poster, representou um exemplo do tanto que pode ser feito em termos de ensino, pesquisa e divulgação a partir de uma pequena mas representativa coleção de artefatos arqueológicos.

\author{
Elaine F.V. Hirata* \\ Maria Beatriz Borba F.lorenzano*
}

